\title{
PENERAPAN SISTEM ANTRIAN SEBAGAI UPAYA MENGOPTIMALKAN PELAYANAN PEMBAYARAN PAJAK KENDARAAN BERMOTOR DI KANTOR SAMSAT KOTA PALU
}

\author{
Serlyng ${ }^{1}$, A.I. Jaya ${ }^{2}$, dan A. Sahari ${ }^{3}$ \\ 1,2,3 Program Studi Matematika Jurusan Matematika \\ Fakultas Matematika dan IImu Pengetahuan Alam Universitas Tadulako \\ Jalan Sukarno-Hatta Km. 9 Palu 94118, Indonesia \\ 1elynserlyn@gmail.com, 2jayaindraagus@gmail.com, ${ }^{3}$ Agus_Sh@yahoo.com
}

\begin{abstract}
One phenomenon that often occurs in daily life is a queue phenomenon. When queue is too long, it will harm the customer, therefore improving system servicing and optimizing the number of servers expected to reduce the queue, so the process of waiting does not happen too long. In the process of payment of motor vehicle tax at SAMSAT Palu City, it has been known that the queuing system using model Multi Channel- Multi Phase. This system occurs if there are two or more facilities serving with services more than one phase. The ains of this researeh are to determine the characteristics of quene system and to know the number of person that required in the process of rehiele tax payment so that the service becomes optimal. The results stated that each phases of 1,2,3 and 4 is consist of 2 person, and motor vehicle tax payment servises in SAMSAT Palu is 108,9 minutes for one customer. Once optimized, an alternative solution to queue problem in SAMSAT Palu city is added person. The addition of 3 person at phase 1, 4 person phase 2, 5 person at phase 3 and phase 4 . Will shorten the queue length from $(108,9)$ minutes to $(29,76)$ minutes for one customer.
\end{abstract}

Keywords $\quad$ : Model Multi Channel- Multi Phase, Samsat Queue.

\section{ABSTRAK}

Salah satu fenomena yang sering terjadi dalam kehidupan sehari-hari adalah fenomena antrian. Antrian yang terlalu panjang akan merugikan pelanggan, oleh sebab itu perbaikan sistem pelayanan dan pengoptimalan banyaknya orang diharapkan mampu mengurangi antrian, sehingga proses menunggu tidak terjadi terlalu lama. Pada proses pembayaran pajak kendaraan bermotor di SAMSAT Kota Palu telah diketahui bahwa sistem antriannya menggunakan model Multi Channe/ - Multi Phase yaitu sistem ini terjadi jika ada dua atau lebih fasilitas pelayanan dengan pelayanannya lebih dari satu fase. Tujuan dari penulisan skripsi ini adalah untuk menentukan karakteristik dan mengetahui banyaknya orang yang diperlukan pada proses pelayanan pembayaran pajak kendaraan bermotor sehingga pelayanannya menjadi optimal. Hasil penelitian menyatakan bahwa fase 1,2,3 dan 4 masing-masing terdiri 2 orang, dengan model Multi Channel - Multi Phase serta lama pembayaran pajak kendaraan bermotor di SAMSAT Kota Palu selama 108,9 menit per pelanggan. Setelah dioptimalkan, didapatkan solusi alternatif dari permasalahan antrian di SAMSAT Kota Palu berupa penambahan orang. Setelah penambahan 
orang fase 1 terdiri 3 orang, fase 2 terdiri 4 orang, fase 3 terdiri 5 orang dan fase 4 terdiri 5 orang. Solusi ini berhasil mengurangi lama antrian dari $(108,9)$ menit menjadi $(29,76)$ menit per pelanggan.

\section{Kata kunci : : Model Multi Channel - Multi Phase, Antrian Samsat.}

\section{PENDAHULUAN}

\subsection{Latar Belakang}

Salah satu fenomena yang sering terjadi dalam kehidupan sehari-hari adalah fenomena Antrian. Hal tersebut terjadi karena kebutuhan akan suatu pelayanan melebihi kapasitas yang tersedia untuk penyelenggaraan pelayanan tersebut. Antrian yang terlalu panjang akan merugikan pelanggan maupun pengelola tempat pelayanan, sebab jika pelanggan tidak sabar, maka perusahaan akan kehilangan pelanggan Oleh sebab itu, perbaikan sistem pelayanan dan pengoptimalan jumlah server diharapkan mampu mengurangi antrian, sehingga proses menunggu tidak terjadi terlalu lama.

Antrian pembayaran Pajak Kendaraan Bermotor di SAMSAT Kota Palu merupakan pusat tempat pembayaran pajak kendaraan bermotor diwilayah Kota Palu dimana setiap hari begitu banyaknya masyarakat yang melakukan pembayaran pajak. Hal ini disebabkan karena sudah adanya istilah tanggal jatuh tempo pembayaran, sehingga mengakibatkan terjadinya antrian. Kepuasan wajib pajak dalam memproleh pelayanan yang diberikan oleh pengawai kantor SAMSAT cenderung rendah. Berdasarkan wawancara, beberapa keluhan-keluhan yang dilontarkan oleh para wajib pajak terhadap pelayanan pembayaran pajak di SAMSAT Kota Palu diantaranya salah satu masyarakat yang mengeluhkan lamanya proses pelayanan di kantor SAMSAT Kota Palu. la mengatakan "dirinya terpaksa menghabiskan waktu selama dua hari hanya untuk menunggu proses penyelesaian pengurusan pembayaran pajak kendaraan bermotor (STNK). Hal itu disebabkan karena sistem dan mekanisme yang dijalankan oleh petugas sangat rumit dan menyusahkan wajib pajak karena harus berbolakbalik dari satu loket ke loket lainnya"(www.antarasulteng.com, kamis 05 Februari 2012).

\subsection{Tujuan}

1. Menentukan karakteristik dari sistem antrian pembayaran pajak kendaraan bermotor di Kantor SAMSAT Kota Palu.

2. Mengetahui jumlah orang yang diperlukan pada proses pelayanan pembayaran pajak kendaraan bermotor sehingga pelayanannya menjadi optimal.

\section{TINJAUAN PUSTAKA}

\subsection{Pengertian Antrian}

Menurut Heizer \& Render (2011) teori antrian (queuing theory) adalah ilmu pengetahuan tentang bentuk antrian yang merupakan sebuah bagian penting operasi dan juga alat-alat yang sangat berharga bagimanajer operasi. Menurut Taha(1997), fenomena menunggu (antri) 
adalah hasil langsung dari keacakan dalam operasi pelayanan. Menurut Prawirosentano (2005), Secara umum antrian dipengaruhi oleh beberapa sifat dasar yang merupakan karakteristik antrian, yaitu sumber masukan (input), disiplin antrian, tingkat kedatangan dan tingkat pelayanan, panjang antrian, dan keluar (output).

Menurut Subagyo (2000), terdapat empat jenis sistem antrian, yaitu jenis antrian satu jalur satu tahap pelayanan (Single-Channe/ Single Phase), jenis antrian satu jalur lebih dari satu tahap (Single Channel Multi Phase), jenis antrian lebih dari dua jalur pelayanan tetapi hanya memiliki satu tahap (Multi Chane/ Single Phase) dan jenis antrian lebih dari satu jalur dan tahap (Multi Channel Multi Phase).

\subsection{Model Antrian}

Sistem antrian jalur berganda terdapat dua atau lebih jalur atau sistem pelayanan yang tersedia untuk menangani pelanggan yang akan datang. Asumsi bahwa pelanggan yang menunggu pelayanan membentuk satu jalur yang akan dilayani pada stasiun pelayanan yang tersedia pertama kali pada saat itu. Pola kedatangaan mengikuti distribusi Poisson dan waktu pelayan mengikuti distribusi eksponensial negatif. Pelayanan dilakukan secara First-Come First-Served, dan semua stasiun pelayanan yang sama. Pada penelitian ini penulis menggunakan rumus antrian $M / M / S$ yaitu terdapat lebih dari satu jalur pelayanan. Rumus antrian untuk model ini adalah sebagai berikut (Taha, 1996):

1) Probabilitas terdapat 0 pelanggan dalam sistem (tidak adanya pelanggan dalam sistem).

$$
P_{0}=\frac{1}{\left[\sum_{n=0}^{M-1} \frac{1}{n !}\left(\frac{\lambda}{\mu}\right)^{n}\right]+\frac{1}{M !}\left(\frac{\lambda}{\mu}\right)^{M} \frac{M \cdot \mu}{M \mu-\lambda}} \quad \text { untuk } \mathrm{M} \mu>\lambda
$$

Dimana $\mathrm{M}$ adalah banyaknya jalur yang terbuka, dan $\mathrm{n}$ adalah banyaknya pelanggan.

2) Faktor utilisasi sistem (populasi fasilitas pelayanan sibuk)

$$
\rho=\frac{\lambda}{M \mu}
$$

3) Banyaknya pelanggan dalam antrian

$$
L_{q}=\frac{\lambda \mu\left(\frac{\lambda}{\mu}\right)^{M}}{(M-1) !(M \mu-\lambda)^{2}} P_{0}
$$

4) Waktu yang dihabiskan sebuah pelanggan untuk menunggu dalam antrian

$$
W_{q}=\frac{L_{q}}{\lambda}
$$

5) Banyaknya pelanggan yang menunggu dalam sistem

$$
L_{s}=L_{q}+\frac{\lambda}{\mu}
$$

6) Waktu yang dihabiskan sebuah pelanggan untuk menunggu dalam sistem atau yang sedang dilayani

$$
W_{s}=\frac{L_{s}}{\lambda}
$$


Keterangan:

$\lambda=$ Banyaknya pelanggan yang datang per satuan waktu

$\mu=$ Banyaknya pelanggan yang dilayani per satuan waktu

$M=$ Banyaknya orang

$L_{q}=$ Banyaknya pelanggan yang menunggu dalam antrian

$L_{s}=$ Banyaknya pelanggan yang menunggu dalam sistem

$W_{q}=$ Waktu yang dihabiskan sebuah pelanggan dalam antrian

$W_{s}=$ Waktu yang dihabiskan sebuah pelanggan menunggu dalam sistem

$P_{0}=$ Probabilitas terdapat nol pelanggan dalam sistem.

\section{METODE PENELITIAN}

Data yang di gunakan dalam penelitian ini adalah data primer. Penelitian dilakukan dengan melakukan prosedur di bawah ini:

1. Mempersiapkan penelitian.

2. Mengkaji literatur tentang teori antrian, jenis antrian dan model antrian

3. Mengumpulkan data berupa data kedatangan, data pelayanan, dan data jalur yang terbuka.

4. Membangun model antrian Multi Channel Multi Phase.

5. Uji kedatangan dan waktu pelayanan dengan menggunakan uji Kolmogorov Smirnov

6. Menentukan karakteristik antrian dengan rumus antrian M/M/S (Multiple Channel Query System)

7. Menarik kesimpulan dari hasil penelitian.

\section{HASIL DAN PEMBAHASAN}

\subsection{Analisis Data Model Antrian Yang Diteliti}

Tahap awal penelitian ini adalah dilakukannya observasi pada kantor SAMSAT Kota Palu. Observasi ini dilaksakan pada proses pelayanan pembayaran wajib pajak kendaraan bermotor di wilaya Kota Palu. Hal ini dilaksanakan pada saat pembayaran wajib pajak kendaraan bermotor terjadi antrian pelanggan yang ingin mendapatkan layanan. Berdasarkan Standar Operasional Prosedure (SOP) pada proses pelayanan pembayaran wajib pajak kendaraan bermotor di SAMSAT Kota Palu MAX 30 Menit. Berdasarkan observasi awal, model antrian yang sudah ada pada proses pelayanan pembayaran wajib pajak kendaraan bermotor di SAMSAT Kota Palu berpola M/M/S (Multiple channe/ Query System atau Model Antrian jalur Berganda) dengan arti bahwa pelayanan pembayaran wajib pajak kendaraan bermotor di SAMSAT Kota Palu terdiri atas 4 phase (fase) dengan 2 channel (orang) pada masing-masing server. 
Tabel 1 : Data Kedatangan

\begin{tabular}{|c|c|c|c|}
\hline N0. & $\begin{array}{c}\text { Hari } \\
\text { pengamatan }\end{array}$ & $\begin{array}{c}\text { Jumlah } \\
\text { Kedatangan } \\
\text { (per orang) }\end{array}$ & $\begin{array}{c}\text { Banyak } \\
\text { Orang }\end{array}$ \\
\hline 1 & Senin & 80 & 2 \\
\hline 2 & Selasa & 74 & 2 \\
\hline 3 & Rabu & 76 & 2 \\
\hline \multicolumn{2}{|c|}{ Jumlah } & \multicolumn{2}{|c|}{230} \\
\hline
\end{tabular}

Berdasarkan Tabel 1 dapat diketahui bahwa volume wajib pajak terbanyak yang datang di kantor SAMSAT Kota Palu terjadi pada hari senin yaitu sebanyak 80 orang.

Tabel 2 : Data Antar Kedatangan

\begin{tabular}{|c|c|c|c|c|c|c|c|c|c|c|c|c|c|c|}
\hline \multirow{2}{*}{$\begin{array}{c}\text { Waktu } \\
\text { Pengamatan }\end{array}$} & \multirow{2}{*}{ Pukul } & \multicolumn{3}{|c|}{ Fase 1} & \multicolumn{3}{|c|}{ Fase 2} & \multicolumn{3}{|c|}{ Fase 3} & \multicolumn{3}{|c|}{ Fase 4} & Total \\
\hline & & $\lambda$ & $\mu$ & $M$ & $\lambda$ & $\mu$ & $M$ & $\lambda$ & $\mu$ & $M$ & $\lambda$ & $\mu$ & $M$ & \multirow{3}{*}{108,9 menit } \\
\hline \multirow{2}{*}{$\begin{array}{c}\text { 10/04/2017 } \\
\text { Senin }\end{array}$} & \multirow[b]{2}{*}{$\begin{array}{l}08.00- \\
09.00\end{array}$} & 16 & 9 & 2 & 9 & 6 & 2 & 6 & 4 & 2 & 4 & 4 & 2 & \\
\hline & & \multicolumn{3}{|c|}{$\begin{array}{l}31,76 \\
\text { Menit }\end{array}$} & \multicolumn{3}{|c|}{22,86 menit } & \multicolumn{3}{|c|}{$\begin{array}{l}34,29 \\
\text { menit }\end{array}$} & \multicolumn{3}{|c|}{$\begin{array}{c}20 \\
\text { menit }\end{array}$} & \\
\hline
\end{tabular}

Tabel 3 : Data Tersibuk

\begin{tabular}{|c|c|c|c|c|c|c|c|c|c|}
\hline \multirow{2}{*}{$\begin{array}{c}\text { Waktu } \\
\text { Pengamatan }\end{array}$} & \multirow[t]{2}{*}{ Pukul } & \multicolumn{2}{|c|}{ Fase 1} & \multicolumn{2}{|c|}{ Fase 2} & \multicolumn{2}{|c|}{ Fase 3} & \multicolumn{2}{|c|}{ Fase 4} \\
\hline & & $\lambda$ & $\mu$ & $\lambda$ & $\mu$ & $\lambda$ & $\mu$ & $\lambda$ & $\mu$ \\
\hline \multirow{6}{*}{$\begin{array}{c}\text { 10/04/2017 } \\
\text { Senin }\end{array}$} & $08.00-09.00$ & 16 & 9 & 9 & 6 & 6 & 4 & 4 & 4 \\
\hline & $09.00-10.00$ & 10 & 11 & 11 & 6 & 6 & 5 & 5 & 5 \\
\hline & $10.00-11.00$ & 12 & 11 & 11 & 8 & 8 & 4 & 4 & 4 \\
\hline & $11.00-12.00$ & 13 & 9 & 9 & 6 & 6 & 5 & 5 & 5 \\
\hline & $13.00-14.00$ & 15 & 11 & 11 & 6 & 6 & 4 & 4 & 4 \\
\hline & $14.00-15.00$ & 14 & 12 & 12 & 7 & 7 & 4 & 4 & 4 \\
\hline \multirow{6}{*}{$\begin{array}{c}\text { 11/04/2017 } \\
\text { Selasa }\end{array}$} & $08.00-09.00$ & 15 & 13 & 13 & 8 & 8 & 5 & 5 & 5 \\
\hline & $09.00-10.00$ & 11 & 9 & 9 & 8 & 8 & 5 & 5 & 5 \\
\hline & $10.00-11.00$ & 9 & 8 & 8 & 7 & 7 & 6 & 6 & 6 \\
\hline & $11.00-12.00$ & 17 & 12 & 12 & 9 & 9 & 5 & 5 & 5 \\
\hline & $13.00-14.00$ & 13 & 13 & 10 & 6 & 6 & 5 & 5 & 5 \\
\hline & $14.00-15.00$ & 9 & 8 & 8 & 7 & 7 & 6 & 6 & 6 \\
\hline \multirow{6}{*}{$\begin{array}{c}\text { 12/04/2017 } \\
\text { Rabu }\end{array}$} & $08.00-09.00$ & 20 & 14 & 14 & 8 & 8 & 5 & 5 & 5 \\
\hline & $09.00-10.00$ & 10 & 10 & 10 & 8 & 8 & 5 & 5 & 5 \\
\hline & $10.00-11.00$ & 14 & 10 & 10 & 8 & 8 & 7 & 7 & 7 \\
\hline & $11.00-12.00$ & 11 & 9 & 9 & 8 & 8 & 5 & 5 & 5 \\
\hline & $13.00-14.00$ & 9 & 9 & 9 & 6 & 6 & 6 & 6 & 6 \\
\hline & $14.00-15.00$ & 12 & 10 & 10 & 7 & 7 & 5 & 5 & 5 \\
\hline
\end{tabular}


Pada Tabel 3 terlihat bahwa rata-rata kedatangan pelanggan pada kondisi ramai (08.00-09.00 jam) selama 108,9 menit per pelanggan. Rata-rata kedatangan pelanggan terbanyak terjadi pada kondisi ramai yang berarti pada jam itu adalah jam sibuk pada kantor SAMSAT Kota Palu.

\subsection{Uji Kolmogorov Smirnov Satu Sampel}

Statistik Uji Kolmogorov Smirnov satu sampel digunakan untuk menguji data kedatangan apakah berdistribusi Poisson atau tidak dengan menggunakan program SPSS 12.0 for Windows. Adapun langkah-langkahnya adalah sebagai berikut:

1) Pola kedatangan akan diuji apakah berdistribusi Poisson atau tidak melalui hipotesis pengujian :

$\mathrm{H}_{0}: \mu$ : Pola kedatangan satker berdistribusi Poisson

$\mathrm{H}_{1}: \mu$ : Pola kedatangan satker tidak berdistribusi Poisson

$\mathrm{H}_{0}: \mu$ : Waktu pelayanan satker berdistribusi Eksponensial

$\mathrm{H}_{1}: \mu$ : Waktu pelayanan tidak berdistribusi Eksponensial

2) Adapun rumus Kolmogorov Smirnov yang digunakan dalam penelitian ini adalah

$\mathrm{D}=$ Maks $\left|\mathrm{F}_{\mathrm{a}}(\mathrm{x})-\mathrm{F}_{\mathrm{e}}(\mathrm{x})\right|$

3) Taraf signifikan $5 \%$ atau 0,05

4) Kriteria pengujian

$\mathrm{H}_{0}$ diterima apabila Komlogorov Smirnov Hitung $\leq$ Kolmogorov Smirnov Tabel.

$\mathrm{H}_{0}$ ditolak apabila Komlogorov Smirnov Hitung > Kolmogorov Smirnov Tabel.

5) Hasilnya disajikan sebagai berikut.

Tabel 4 : Hasil Uji Kecocokan Distribusi Pola Kedatangan Menggunakan Program SPSS 12.0 For Windows.

\begin{tabular}{|c|c|c|c|c|c|}
\hline \multicolumn{6}{|c|}{ One-Sample Kolmogorov-Smirnov Test } \\
\hline & & phaes 1 & phaes 2 & phaes 3 & phaes 4 \\
\hline$N$ & & 6 & 6 & 6 & 6 \\
\hline Poisson Parameter ${ }^{a, b}$ & Mean & 13,3333 & 10,5000 & 6,5000 & 4,3333 \\
\hline \multirow[t]{3}{*}{ Most Extreme Differences } & Absolute &, 189 &, 279 & ,369 & ,371 \\
\hline & Positive & , 189 &, 258 & ,208 & .269 \\
\hline & Negative &,- 154 &,- 279 &,- 369 &,- 371 \\
\hline Kolmogorov-Smirnov Z & & .464 & 684 & ,904 & ,909 \\
\hline Asymp. Sig. (2-tailed) & & 983 &, 737 & 387 & 380 \\
\hline
\end{tabular}

Tabel 5 : Hasil Uji Kecocokan Ditribusi Waktu Pelayanan Menggunakan Program SPSS 12.0 For Windows

\begin{tabular}{|ll|r|r|r|r|}
\hline \multicolumn{7}{|c|}{ One-Sample Kolmogorov-Smirnov Test } \\
\hline \multicolumn{2}{|c|}{} & phase 1 & phase 2 & phase 3 & phase 4 \\
\hline $\mathrm{N}$ & 6 & 6 & 6 & 6 \\
Exponential parameter. $^{\text {a.b }}$ & Mean & 13,3333 & 10,5000 & 6,5000 & 4,3333 \\
Most Extreme Differences & Absolute &, 528 &, 576 &, 603 &, 603 \\
& Positive &, 301 &, 319 &, 292 &, 315 \\
& Negative &,- 528 &,- 576 &,- 603 &,- 603 \\
& & 1,292 & 1,410 & 1,476 & 1,476 \\
Kolmogorov-Smirnov Z &, 071 &, 038 &, 026 &, 026 \\
Asymp. Sig. (2-tailed) & &, 071 & \\
\hline
\end{tabular}


a) Dari Tabel 4 hasil pengujian diatas diperoleh nilai simpangan positif $\left(D^{+}\right)$adalah 0,189 dan simpangan negatifnya sebesar $-0,154$ sehingga simpangan terbesar (absolute) yaitu 0,189 dan nilai peluangnya adalah 0,983. Karena nilai peluangnya lebih besar dari taraf signifikan 0,05 maka dapat disimpulkan $\mathrm{H}_{0}$ diterima yang artinya bahwa pola kedatangan mengikuti distribusi Poisson.

b) Dari Tabel 5 hasil pengujian diatas diperoleh nilai simpangan positif $\left(D^{+}\right)$adalah 0,301 dan simpangan negatifnya sebesar -0,528 sehingga simpangan terbesar (absolute) yaitu 0,528 dan nilai peluangnya adalah 0,71. Karena nilai peluangnya lebih besar dari taraf signifikan 0,05 maka dapat disimpulkan $\mathrm{H}_{0}$ diterima yang artinya bahwa waktu pelayanan mengikuti distribusi Eksponensial.

\subsection{Analisis Sitem Antrian Dengan Model Antrian Multiple Channel Query System atau M/M/S}

Berikut ini disajikan hasil perhitungan analisis antrian dengan menggunakan model antrian jalur berganda (M/M/S). Untuk nilai $\lambda, \mu, L q$ dan $L s$ digunakan aturan pembulatan variabel diskrit yaitu variabel yang besarannya tidak dapat menempati semua nilai, selalu berupa bilangan bulat dan umumnya diperoleh dari hasil pencacahan dan pembulatannya selalu naik berapapun angka dibelakang koma (FNIStatistics, 2017).

Tabel 6 : pada kondisi ramai hari senin pukul 08.00-09.00

\begin{tabular}{|c|c|c|c|c|}
\hline $\mathrm{T}$ (menit) & $\begin{array}{c}\text { Fase } \\
1\end{array}$ & Fase 2 & Fase 3 & Fase 4 \\
\hline $\boldsymbol{\lambda}$ & 16 & 9 & 6 & 4 \\
\hline $\boldsymbol{\mu}$ & 9 & 6 & 4 & 4 \\
\hline $\mathrm{M}$ (orang) & 2 & 2 & 2 & 2 \\
\hline $\boldsymbol{\rho}(\%)$ & 0,89 & 0,75 & 0,75 & 0,5 \\
\hline Lq(plg) & 6,69 & 1,93 & 1,93 & 0,33 \\
\hline Ls(plg) & 8,47 & 3,43 & 3,43 & 1,33 \\
\hline$W q($ menit) & 25,1 & 12,86 & 19,29 & 5 \\
\hline$W s$ (menit) & 31,76 & 22,86 & 34,29 & 20 \\
\hline
\end{tabular}

\section{4. $\quad$ Analisis Model Antrian Dengan Melakukan Penambahan Orang}

Setelah mengamati model antrian Multi Channel - Multi Phase pada kantor SAMSAT didapatkan karakteristik antrian yang diketahui bahwa sistem antrian belum memenuhi target waktu pembayaran pajak terlihat pada fase 1, 2, 3, dan 4 masih jauh dari target yaitu kurang dari 7 menit sehingga dibutuhkan suatu solusi alternatif untuk memenuhi target sehingga butuh tambahan orang di setiap fase agar dapat mengoptimalkan pelayanan di kantor SAMSAT. Pada analisis model antrian penambahan orang dapat diasumsikan banyaknya kedatangan pelanggan tetap dan banyaknya pelanggan yang dilayani bertambah sebanyak pelanggan yang ditambahkan. 
Tabel 7 : hasil perhitungan Karakteristik Antrian sebelum penambahan orang

\begin{tabular}{|c|c|c|c|c|c|}
\hline $\mathrm{T}$ (menit) & Fase 1 & Fase 2 & Fase 3 & Fase 4 & Total \\
\hline$\lambda$ & 16 & 9 & 6 & 4 & \\
\hline$\mu$ & 9 & 6 & 4 & 4 & \\
\hline $\mathrm{M}$ (orang) & 2 & 2 & 2 & 2 & \\
\hline$\rho(\%)$ & 0,89 & 0,75 & 0,75 & 0,5 & \\
\hline$\angle q(p / g)$ & 6,69 & 1,93 & 1,93 & 0,33 & 10,88 \\
\hline$L s(p / g)$ & 8,47 & 3,43 & 3,43 & 1,33 & 16,66 \\
\hline$W$ (menit) & 25,1 & 12,86 & 19,29 & 5 & 62,25 \\
\hline$W s(m e n i t)$ & 31,76 & 22,86 & 34,29 & 20 & 108,9 \\
\hline
\end{tabular}

Berdasarkan Tabel 7 menunjukkan bahwa nilai rata-rata kedatangan dalam sistem antrian (Ws total) selama 108,9 menit. Hal ini masih jauh dari target yaitu kurang dari 7 menit sehingga dibutuhkan suatu solusi alternatif untuk memenuhi target.

\subsection{Optimalisasi Sistem Antrian di SAMSAT Kota Palu}

Telah diketahui bahwa sistem antrian belum memenuhu target waktu pembayaran pajak yang masih lebih dari 7 menit sehinggah tdk memenuhi Standar Operasional Prosedure (SOP) pada proses pelayanan pembayaran wajib pajak kendaraan bermotor di SAMSAT Kota Palu MAX 30 Menit . Dengan adanya hal ini maka diperlukan suatu optimalisasi kinerja loket-loket pelayanan itu sendiri. Seperti program utama bahwa untuk memenuhi target maka jumlah orang pada tiap fase harus diperbanyak untuk mempercepat kinerja. Jika sistem antrian masih belum memenuhi target maka harus dimasukkan input baru dengan penambahan orang jika sistem antrian sudah memenuhi target, maka kombinasi banyak orang itulah yang merupakan solusi alternatif yang optimal agar hasil optimalisasi dapat dilihat dari Tabel 8 :

Tabel 8 : hasil perhitungan Karakteristik Antrian Setelah Penambahan orang Menggunakan Aplikasi POM-QM For Windows

\begin{tabular}{|c|c|c|c|c|c|}
\hline $\mathrm{T}$ (menit) & Fase 1 & Fase 2 & Fase 3 & Fase 4 & Total \\
\hline$\lambda$ & 16 & 9 & 6 & 4 & \\
\hline$\mu$ & 10 & 8 & 7 & 7 & \\
\hline M(orang) & 3 & 4 & 5 & 5 & \\
\hline $\boldsymbol{\rho}(\%)$ & 53 & 28 & 17 & 11 & \\
\hline$L q(p / g)$ & 0,31 & 0,01 & 0 & 0 & 0,32 \\
\hline$L s(p / g)$ & 1,91 & 1,14 & 0,86 & 0,57 & 4,48 \\
\hline$W q($ menit) & 1,17 & 0,08 & 0 & 0 & 1,25 \\
\hline$W s$ (menit) & 7,17 & 7,58 & 7,45 & 7,56 & 29,76 \\
\hline
\end{tabular}


Dari Tabel 8 tampak bahwa sistem antrian sudah memenuhi target yaitu $W s$ kurang dari 7 menit. Hal ini diperlihatkan dari nilai Ws total selama 29,76 menit yang menunjukkan bahwa penambahan orang lebih baik karena waktu pelayanan yang ditetapkan SAMSAT Kota Palu yaitu 30 Menit sesuai Standar Operasional Pelayanan (SOP). Oleh karena itu, sistem antrian dengan kombinasi orang seperti berikut merupakan salah satu solusi alternatif yang optimal.

\section{KESIMPULAN}

1. Karakteristik dari sistem antrian pembayaran pajak kendaraan bermotor diKantor SAMSAT diKota Palu menggunakan Multi Chanel - Multi Phase.

2. Berdasarkan hasil dan pembahasan yang telah dilakukan, dapat disimpulkan bahwa setelah di lakukan penambahan orang pada fase 1,2,3 dan 4 masing-masing penambahan fase 1 terdiri 1, fase 2 terdiri 2, fase 3 terdiri 3 dan fase 4 terdiri 3 orang. Model antrian $M / M / s$ sudah memenuhi target yaitu nilai $W s$ total selama $29,76 \approx 30$ menit. Oleh karena itu, sistem antrian dengan kombinasi orang seperti di atas merupakan solusi alternatif yang optimal.

\section{DAFTAR PUSTAKA}

[1]. Handoko, T, H, Manajemen Personalia dan Sumber Daya Manusia, BPFE, 1995, Yogyakarta.

[2]. Prawirosentano, S, Riset Operasi dan Ekonofisika, Bumi Aksara, 2005, Jakarta.

[3]. Subagyo,P, Dasar-Dasar Operation Research, BPFE, 2000, Yogyakarta.

[4]. Taha, H, A., Riset Operasi Suatu Pengantar, Edisi Kelima, Jilid 2, Alih Bahasa: Daniel Wirajaya, Binarupa Aksara, 1996, Jakarta.

[5]. http://www.antarasulteng.com/berita/1459/samsat-palu-dan-permasalahannya.

[6]. https://www.kbbi.kata.web.id/pengoptimalan 